\title{
Erratum to: The advantages of SMRT sequencing
}

Richard J. Roberts ${ }^{1 *}$, Mauricio O. Carneiro ${ }^{2}$ and Michael C. Schatz ${ }^{3}$

\section{Erratum}

It has been highlighted that the original manuscript [1] has been published in duplicate and indexed on the SpringerLink platform. The duplicate article [2] is not the official version of this manuscript. We apologise for any confusion caused by this discrepancy and acknowledge the former, original manuscript [1], also indexed on the PubMed platform, as the official version of this work on behalf of the author.

The publisher apologises for these errors.

\section{Author details}

'New England Biolabs, 240 County Road, Ipswich, MA 01938, USA. Broad Institute of Harvard and MIT, Cambridge, MA 02142, USA. ${ }^{3}$ Simons Center for Quantitative Biology, Cold Spring Harbor Laboratory, Cold Spring Harbor, NY 11743, USA.

Published online: 16 August 2017

\section{References}

1. Roberts RJ, Carneiro MO, Schatz MC. The advantages of SMRT sequencing. Genome biology. 2013;14(6):405.

2. Roberts RJ, Carneiro MO, Schatz MC. The advantages of SMRT sequencing. Genome biology. 2013;14(7):405.

\footnotetext{
* Correspondence: roberts@neb.com

${ }^{1}$ New England Biolabs, 240 County Road, Ipswich, MA 01938, USA
} 